\title{
Evaluation of the interfacial and interlaminar shear strength of carbon fiber reinforced polycarbonate made by a unidirectional sheet
}

\author{
K. Tanaka ${ }^{1}$, M. Suzue ${ }^{1}$, S. Isshiki ${ }^{1}$, M. Shinohara ${ }^{2}$ \& T. Katayama ${ }^{1}$ \\ ${ }^{I}$ Department of Biomedical Engineering, Doshisha University, Japan \\ ${ }^{2}$ Department of Mechanical Engineering, \\ Maizuru National College of Technology, Japan
}

\begin{abstract}
Carbon Fiber Reinforced Plastics (CFRP) have been attracting attention in the automotive industry for their light-weighted properties. Thermoset plastics are mainly used as a matrix of CFRP in the aerospace industry. Thermosetting resin takes a long time for molding and this results in high costs. On the other hand, Carbon Fiber Reinforced Thermoplastics (CFRTP) are recyclable, good in productivity and excellent in impact strength. Thus, they are expected to be widely applied within the industry. Polycarbonate (PC) is excellent in impact resistance that does not change even at low temperatures. Therefore, PC can be expected to be applied as matrices of CFRTP. PC with higher-molecular-weight improves its impact resistance, but at the same time, increases its viscosity and deteriorates impregnation of the continuous fibers. Therefore, improvements in moldability of $\mathrm{CF} / \mathrm{PC}$ are required. To improve the quality of the molded $\mathrm{CF} / \mathrm{PC}$, $\mathrm{CF} / \mathrm{PC}$ thermoplastic prepreg, in which carbon fabrics or unidirectional carbon sheets are pre-impregnated with PC, were developed. In this study, carbon fiber reinforced polycarbonate $(\mathrm{CF} / \mathrm{PC})$ laminated composites were molded with thermoplastic prepregs of unidirectional (UD) sheets; moldability and mechanical properties of CF/PC laminated composites were evaluated.

Keywords: carbon fiber, polycarbonate (PC), thermoplastics, CFRTP, UD sheet, thermoplastic prepreg.
\end{abstract}




\section{Introduction}

Carbon Fiber Reinforced Plastics (CFRP) have advantages in high-specific strength and high-specific modulus, hence the demand of CFRP is increasing in the aerospace, automotive and sports industries [1-3]. As the FRP using thermoset resin cannot be melted or reformed after molding, recycling is difficult. On the other hand, Carbon Fiber Reinforced Thermoplastics (CFRTP) are recyclable, good in productivity and excellent in impact strength thus they are expected to be widely applied within the industry $[4,5]$. Polycarbonate (PC) has high impact resistance which is even at low temperatures, high heat resistance and high weatherability compared to other plastics. Thus it is expected to be used as the matrix of CFRTP. Due to high viscosity and poor impregnation of PC resin to fabrics, Carbon Fiber Reinforced Polycarbonate (CF/PC) is recognized to be difficult for molding and improvements in moldability of $\mathrm{CF} / \mathrm{PC}$ are required. In previous studies, CFRTP composites, using PC for a matrix (CF/PC), were molded by the vacuum assisted high-speed compression molding method [6]. Even using a vacuum assisted high-speed compression molding, it remains a problem that resin rich area causes poor formability, during the molding of $\mathrm{CF} / \mathrm{PC}$ with high molecular weight $(30,000)$. In this study, carbon fiber reinforced polycarbonate $(\mathrm{CF} / \mathrm{PC})$ was molded with UD sheets in which unidirectional carbon sheet is pre-impregnated with $\mathrm{PC}$ as semi-products; moldability and mechanical properties of $\mathrm{CF} / \mathrm{PC}$ were evaluated.

\section{Materials and experimental procedure}

\subsection{Materials and molding process}

A UD sheet (Teijin Chemicals Ltd., Japan), impregnated unidirectional carbon sheet with PC (AD5503; molecular weight 15,000 and K1300; molecular weight $30,000)$ and PA6 were used. Two kinds of PC were used to reveal the influence of molecular weight on their mechanical properties. PA6 was used for the competitor to PC, as PA6 are engineering plastics, having high impact resistance, which are commonly used in CFRTP. Reinforcement of the UD sheet was unidirectional spread carbon fiber (elastic modulus of 240GPa, tensile strength of 4.90GPa), which had $110 \mathrm{~mm}$ in width, $80 \mu \mathrm{m}$ in thickness and $54 \%$ in $\mathrm{V}_{\mathrm{f}}$.

$\mathrm{CF} / \mathrm{PC}(\mathrm{K}-1300), \mathrm{CF} / \mathrm{PC}$ (AD5503) and CF/PA6 laminated composites were molded by a hot press molding machine. The UD sheet was laminated so as to be $100 \mathrm{~mm}$ in width, $200 \mathrm{~mm}$ in length $2 \mathrm{~mm}$ in thickness and $\left[0^{\circ} / 90^{\circ}\right]_{14 \mathrm{~s}}$. Each molding condition is shown in Table 1 . In order to evaluate the impregnation of the resin, cross sections of the specimens were observed by using a confocal microscope (OPTELICS H1200 Lasertec). 
Table 1: Molding condition of the laminated composites.

\begin{tabular}{|c|c|c|c|c|}
\hline Specimens & $\begin{array}{c}\text { Maximum } \\
\text { Temperature } \\
{\left[{ }^{\circ} \mathrm{C}\right]}\end{array}$ & $\begin{array}{c}\text { Pressure } \\
{[\mathrm{MPa}]}\end{array}$ & $\begin{array}{c}\text { Holding time } \\
\text { at maximum } \\
\text { temperature }[\mathrm{s}]\end{array}$ & $\begin{array}{c}\mathrm{V}_{\mathrm{f}} \\
{[\%]}\end{array}$ \\
\cline { 1 - 2 } $\mathrm{CF} / \mathrm{PC}(\mathrm{K} 1300)$ & 300 & \multirow{2}{*}{2} & 90 & 54 \\
\cline { 1 - 2 } $\mathrm{CF} / \mathrm{PC}(\mathrm{AD} 5503)$ & 270 & & & \\
\cline { 1 - 2 } $\mathrm{CF} / \mathrm{PA} 6$ & \multicolumn{2}{|c|}{20} & & \\
\hline
\end{tabular}

\subsection{Single fiber pull-out test}

Single fiber pull-out tests were conducted to evaluate the interfacial adhesion between the matrix and fibers. Interfacial shear strengths of CF/PC (K-1300) and $\mathrm{CF} / \mathrm{PC}$ (AD5503) were compared to CF/PA6. The same carbon fibers used in UD sheets were used for single fiber pull-out tests. Fig. 1 shows the schematic drawing of preparing the pull-out specimen. After a single fiber was glued to the tab with adhesive, the tab was attached to a micromanipulator. The resin was placed using the micromanipulator on the aluminum plate which was heated at molding temperature, and the single fiber was embedded to the matrix. Pull-out tests were performed using an electro hydraulic servo controlled testing machine for micro materials (MMT-11N, Shimadzu Co., Japan). After chucking a specimen, the supporting part of the tab was cut and the pull-out test was conducted with a constant displacement rate of $1.67 \times 10^{-3} \mathrm{~mm} / \mathrm{s}(0.1 \mathrm{~mm} / \mathrm{min})$. Fig. 2 shows the schematic drawing of the pull-out test. Interfacial shear strength was calculated by the following equation

$$
\tau=\frac{F_{\max }}{\pi d l}
$$

where $F_{\max }$ : maximum load, $d$ : fiber diameter and $l$ : embedded fiber length.

The embedded length $l$ was measured from each pulled-out fiber observed by SEM.

\subsection{Three point bending test for short beam specimens}

One of the weaknesses in mechanical properties of laminated composite materials is the low interlaminar shear strength. Three point bending tests for short beam specimens were conducted by universal material testing machine (INSTRON 5566), following the recommended testing procedures as described in JIS-K7057. Two types of specimens whose outermost layers were $0^{\circ}$ and $90^{\circ}$ were prepared for testing. The length and width of specimen are $20 \mathrm{~mm}$ and $10 \mathrm{~mm}$ respectively. The span length was set for $10 \mathrm{~mm}$. Bending load was applied to the specimen at a displacement rate of $5.0 \mathrm{~mm} / \mathrm{min}$. 


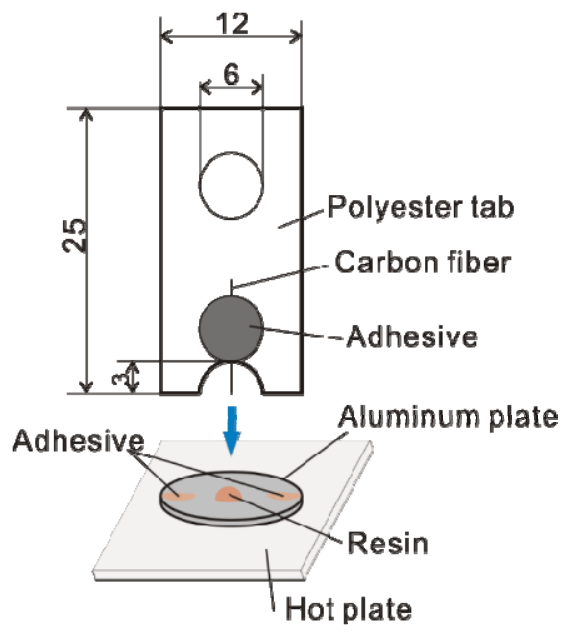

Figure 1: Preparation of pull-out specimen.

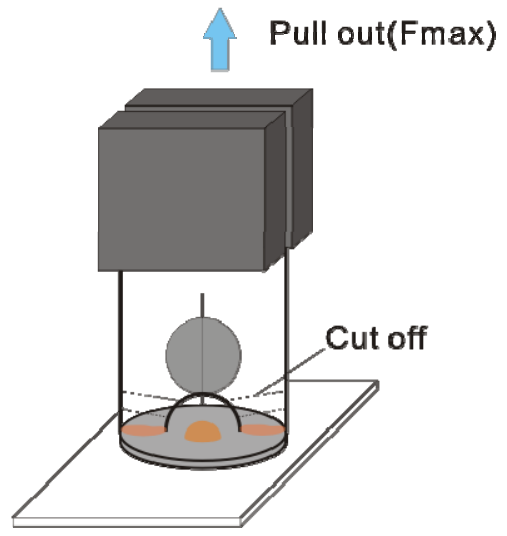

Figure 2: Pull-out test.

\section{Results and discussion}

\subsection{Evaluation of impregnation}

Fig. 3 shows the cross section of molded laminated composites. Regardless of resin, cross sections of the molded products shows good resin impregnation. The void fraction was calculated from the cross section observation by confocal microscope. Void fractions of the CF/PC (K-1300), CF/PC (AD5503) and $\mathrm{CF} / \mathrm{PA} 6$ were $1.06,0.81$ and $0.91 \%$ respectively, showing a good quality of the laminated composites. 


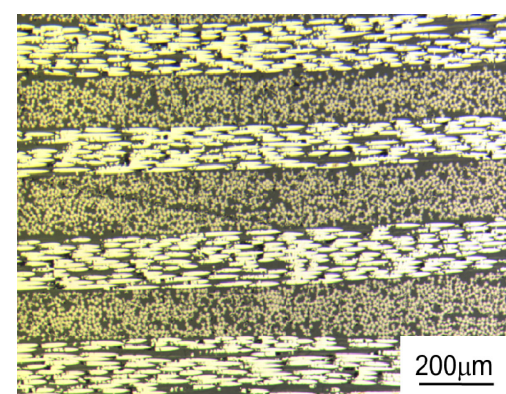

(a) $\mathrm{CF} / \mathrm{PC}(\mathrm{K}-1300)$

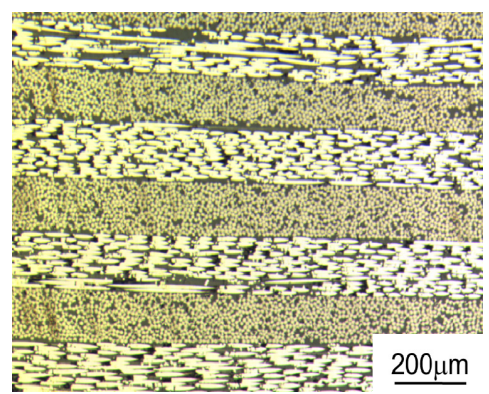

(b) $\mathrm{CF} / \mathrm{PC}(\mathrm{AD}-5503)$

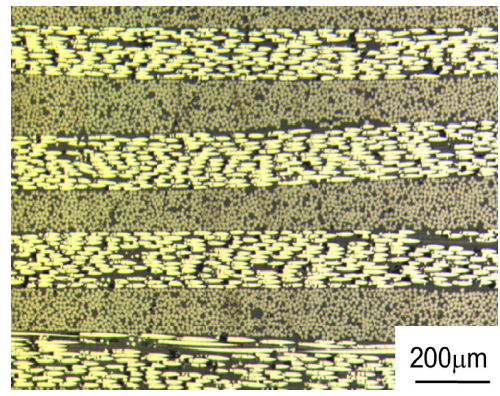

(c) $\mathrm{CF} / \mathrm{PA} 6$

Figure 3: Observation of cross section of laminated composites with confocal microscope.

\subsection{Single fiber pull-out tests}

Fig. 4 shows the relationship between embedded fiber length and maximum load of pull-out tests (the debonding load is plotted in the left, and fiber fracture load is plotted in the right). Fig. 5 shows an example of the pulled-out specimen. The average values of interfacial shear strengths on three kinds of specimens are shown in Table 2.

Table 2: Interfacial shear strength of the pull-out specimens.

\begin{tabular}{|l|c|c|c|}
\hline & $\mathrm{CF} / \mathrm{PC}(\mathrm{K} 1300)$ & $\mathrm{CF} / \mathrm{PC}(\mathrm{AD} 5503)$ & $\mathrm{CF} / \mathrm{PA} 6$ \\
\hline $\begin{array}{l}\text { Interfacial shear } \\
\text { strength [MPa] }\end{array}$ & 68.4 & 53.9 & 40.1 \\
\hline
\end{tabular}


Interfacial shear strength of CF/PA6 is smaller than that of $\mathrm{CF} / \mathrm{PC}(\mathrm{K}-1300)$ and $\mathrm{CF} / \mathrm{PC}(\mathrm{AD}-5503)$. Interfacial shear strength of $\mathrm{CF} / \mathrm{PC}(\mathrm{K}-1300)$ is higher than that of $\mathrm{CF} / \mathrm{PC}$ (AD-5503) by 1.26 times. PC with high molecular weight was found to have higher interfacial strength. Fig. 6 shows interfacial shear strength of this study with the reference data [7-9]. Due to the limited functional group of $\mathrm{PP}$ as reported [8]; interfacial shear strength of $\mathrm{CF} / \mathrm{PP}$ is smaller than that of $\mathrm{CF} / \mathrm{PC}$ and $\mathrm{CF} / \mathrm{PA}$. On the other hand, interfacial shear strength of $\mathrm{CF} / \mathrm{PC}$ (K-1300) is higher than that of CF/PP by 10 times. Epoxy resins are used in a wide range of applications in material with excellent and well balanced adhesion, heat resistance and chemical resistance and so on. Interfacial shear strength of $\mathrm{CF} / \mathrm{EP}$ is about $70.0 \mathrm{MPa}$ as reported [9], while interfacial shear strength of $\mathrm{CF} / \mathrm{PC}(\mathrm{K}-1300)$ is equivalent to that of $\mathrm{CF} / \mathrm{EP}$.

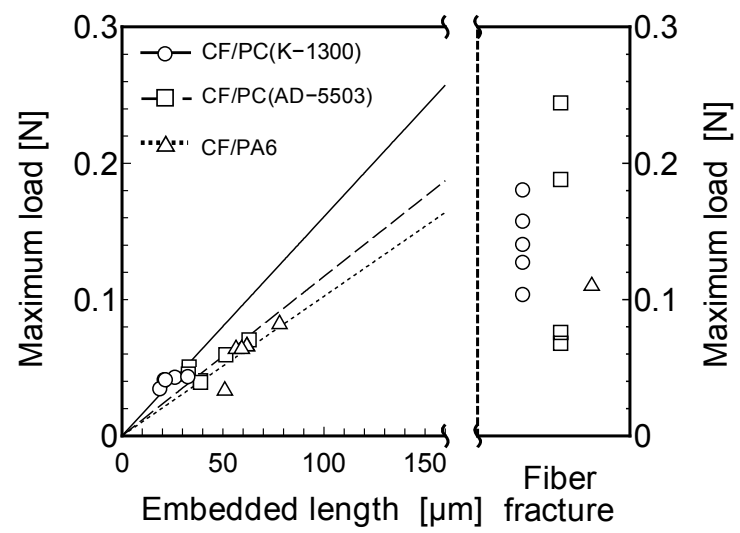

Figure 4: Relationship between embedded fiber length and maximum load of the single fiber pull-out test.

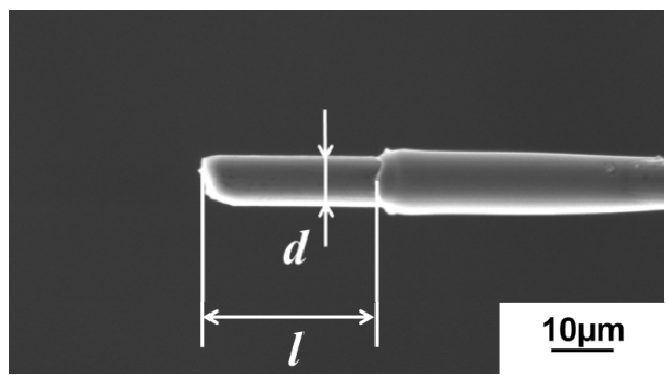

Figure 5: SEM observation of pulled-out specimen. 


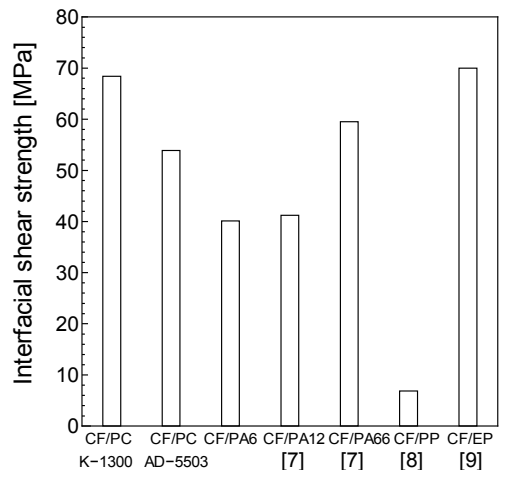

Figure 6: Interfacial shear strength of CF/thermoplastics [7-9].

\subsection{Three point bending test for short beam specimens}

The results of three points bending for short beam specimens of CF/PC (K-1300), $\mathrm{CF} / \mathrm{PC}$ (AD-5503) and CF/PA6 are shown in Fig. 7. Apparent interlaminar shear strengths (outermost layer: $0^{\circ}$ direction) of CF/PC (K-1300), CF/PC (AD5503) and $\mathrm{CF} / \mathrm{PA} 6$ were $63.7 \mathrm{MPa}, 36.5 \mathrm{MPa}$ and $60.0 \mathrm{MPa}$ respectively. Apparent interlaminar shear strengths (outermost layer: $90^{\circ}$ direction) of $\mathrm{CF} / \mathrm{PC}(\mathrm{K}-1300)$, $\mathrm{CF} / \mathrm{PC}$ (AD5503) and $\mathrm{CF} / \mathrm{PA} 6$ were $58.9 \mathrm{MPa}, 31.7 \mathrm{MPa}$ and $59.0 \mathrm{MPa}$ respectively. Apparent interlaminar shear strength of CF/PC (AD5503) whose molecular weight of $\mathrm{PC}$ is small shows smaller value. Charpy impact strength of $\mathrm{PC}(\mathrm{K}-1300)$ and $\mathrm{PC}(\mathrm{AD}-5503)$ were reported to be $89 \mathrm{KJ} / \mathrm{m}^{2}$ and $3 \mathrm{KJ} / \mathrm{m}^{2}[10]$. Charpy impact strength is strongly connected to the brittleness of the resin. Because of the brittle behaviour of PC(AD-5503), CF/PC (AD5503) has lower apparent interlaminar shear strengths compared to the $\mathrm{PC}(\mathrm{K}-1300)$.

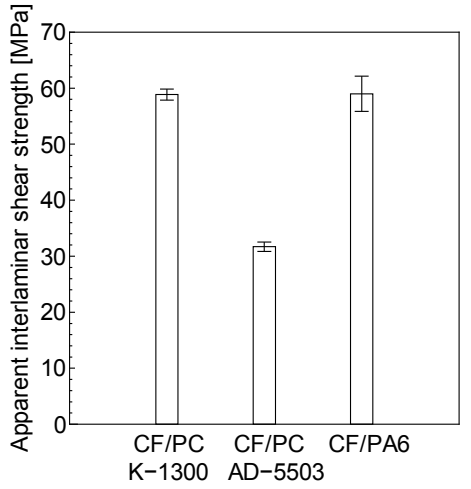

(a) Outermost layer $\left(0^{\circ}\right.$ direction $)$

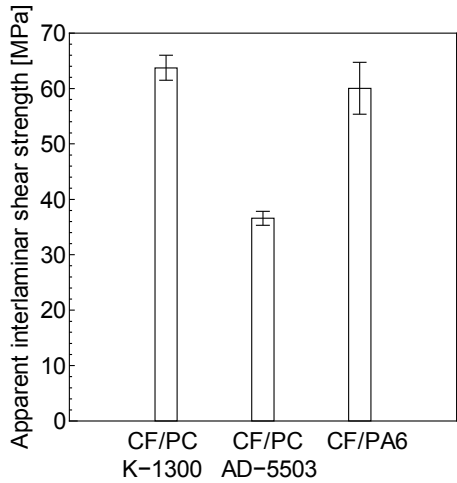

(b) Outermost layer $\left(90^{\circ}\right.$ direction)

Figure 7: Apparent interlaminar shear strength of CF/PC and CF/PA6. 


\section{Conclusion}

Carbon fiber reinforced polycarbonate (CF/PC) and CF/PA6 laminated composites were molded by using UD prepreg sheets and three-point bending properties for short beam specimens were evaluated. Fiber/matrix interfacial properties were also evaluated by pull-out tests. The investigation yielded the following conclusions:

1. By using UD prepreg sheets, highly impregnated carbon fiber reinforced PC, whose molecular weight is 30,000 , can be formed by using UD prepreg sheets.

2. Interfacial shear strengths of $\mathrm{CF} / \mathrm{PC}$ (K-1300), $\mathrm{CF} / \mathrm{PC}$ (AD5503) and $\mathrm{CF} / \mathrm{PA} 6$ were $68.4 \mathrm{MPa}, 53.9 \mathrm{MPa}$ and $40.1 \mathrm{MPa}$ respectively. Interfacial shear strength of $\mathrm{CF} / \mathrm{PC}$ (K-1300) with higher molecular weight is almost same as that of CF/epoxy.

3. Apparent interlaminar shear strengths of $\mathrm{CF} / \mathrm{PC}(\mathrm{K}-1300)$ with higher molecular weight are higher than those of $\mathrm{CF} / \mathrm{PC}$ (AD-5503).

\section{References}

[1] A. Paesano, D. Cohee and G. R. Palmese, Carbon-fibre reinforced thermoplastic materials for rigidizable space systems, Journal of Thermoplastic Composite Material, 16(2), 139-170 (2003).

[2] M. P. Huntley, C. L. Davis, M. Strangwood and S. R. Otto, Comparison of the static and dynamic behaviour of carbon fibre composite golf club shafts, Proc. Inst. Mech. Eng. Pt. L. J. Mater. Des. Appl, 220(4), 229-236 (2006).

[3] C. Soutis, Carbon fiber reinforced plastics in aircraft construction, Material Science and Engineering A, Vol. 412, No. 1-2, pp. 171-176 (2005).

[4] A, R. Offringa, Thermoplastic composites - rapid processing applications, Composites Part A, Vol. 27A, pp. 329-336 (1996).

[5] E. M. Silverman and W. C. Forbes, Cost analysis of thermoplastic composites processing methods for spacecraft structures, Sampe, Journal, Vol. 26, No. 6 pp. 9-15 (1990).

[6] K. Tanaka, H. Kashihara, T. Katayama, Vacuum Assisted High Speed Compression Molding and Evaluation of Mechanical Properties of Continuous Carbon Fiber Reinforced Polycarbonate Composite, Journal of the Society of Materials Science, Japan, Vol. 60, No. 3 pp. 251-258 (2011).

[7] K. Tanaka, S. Mizuno, H. Honda, T. Katayama and S. Enoki, Effect of Water Absorption on the Mechanical Properties of Carbon Fiber/Polyamide Composites, Journal of Solid Mechanics and Materials Engineering, Vol. 7, No. 5, pp. 520-529,2013.

[8] H. Zushi, M. Tamura, I. Ohsawa, K. Uzawa, J. Takahashi and H. Yasuda, Evaluation on Mechanical Properties of Carbon Fiber Reinforced 
Polypropylene, Japan Society for Composite Materials, Vol. 32, No. 4, pp. 153-162 (2006).

[9] J. Koyanagi, J. Kawai, S. Gihara and K. Watanabe, Carbon Fiber/Matrix Interfacial Shear Strength Evaluated by Single Fiber Pull-out test Considering Effects of Resin Meniscus, Experimental mechanics, Vol. 10, No. 4, pp. 407-412 (2010).

[10] Teijin's Grade List. 